\title{
Microstructure Characterization of LTCC Glass-Ceramic Composites with Various Degree of the Introduced Porosity
}

\author{
B. Synkiewicz ${ }^{a, *}$, D. Szwagierczak ${ }^{a}$, J. Ratajczak ${ }^{b}$ And A. Czerwiński ${ }^{b}$ \\ ${ }^{a}$ Institute of Electron Technology, Kraków Division, Zabłocie 39, 30-701 Kraków, Poland \\ ${ }^{b}$ Institute of Electron Technology, Al. Lotników 32/46, 02-668 Warszawa, Poland
}

\begin{abstract}
Low temperature co-fired ceramics (LTCC) materials are commonly used in many areas of microelectronics. Special application includes microwave devices packaging because of the possibility of dielectric constant controlling and the simplicity of the three-dimensional structure obtainment by multilayer lamination. The LTCC composites based on $\mathrm{Al}_{2} \mathrm{O}_{3}$ or cordierite ceramics with $\mathrm{SiO}_{2}-\mathrm{Al}_{2} \mathrm{O}_{3}-\mathrm{B}_{2} \mathrm{O}_{3}$-type glass co-fired with graphite addition are promising low dielectric constant materials. The presence of the introduced inner porosity, as well as not uniform microstructure of a glass-ceramic composite have a strong impact on its mechanical and electrical properties. The composite microstructure can be modified by graphite powder addition at the stage of preparation of slurries for tape casting. The graphite powder addition at the level of $25-50 \mathrm{wt} \%$ leads to the advantageous significant decrease of the dielectric constant although causes also detrimental lowering of mechanical strength of the composite, especially in the case of irregular pores distribution. This work was aimed at characterization of the microstructure, pore distribution and elemental composition for a series of the multilayer laminates containing dense external and porous internal layers with various degree of porosity formed as a result of burnout of graphite. The scanning electron microscopy study showed that both the degree of porosity irregularity and pores distribution and size depend on graphite content in the slurry. Mapping of the composition using energy dispersive spectroscopy method at the cross-section of the composite specimens allowed to observe distribution of the particular elements in the different regions of the multilayer composites.
\end{abstract}

DOI: 10.12693/APhysPolA.134.322

PACS/topics: cordierite, porosity, low temperature co-fired ceramics, SEM analysis, EDS analysis

\section{Introduction}

For high frequency, high speed, high density electronic circuits, low dielectric permittivity of materials used for substrates and packages is a very advantageous feature $[1-5]$. Besides properly tailored composition, introduction of controlled porosity is an additional manner of lowering effective dielectric permittivity of the materials [6-9]. LTCC technology can be utilized as a tool for preparation of multilayer structures which are characterized by low dielectric permittivity due to stacking, lamination and co-firing of dense external layers and porous internal layers [8, 9].

Porosity introduction into a ceramic body strongly influences many electrical (resistance, dielectric constant, dielectric loss), mechanical and thermal properties. In some applications porosity is a detrimental factor, although for some specific goals it may be a fully desired and intentionally designed feature of the solid body. Namely, porosity can be utilized for lowering dielectric permittivity of materials destined for microwave substrates. Both the amount and the character of the porosity (size, shape, open or closed structure, homogeneity of pores distribution, coordination number) are crucial for the porosity-property relation. Well known methods of porosity obtainment are:

*corresponding author; e-mail: synkiewicz@ite.waw.pl
- addition of polymer spheres, carbon particles, carbon fibers and their subsequent burnout;

- addition of hollow glass or ceramic microspheres;

- addition of metallic particles with a higher thermal expansion than the ceramic matrix;

- use of mesoporous silica with controlled structure of pores (for example nanoporous silica/PMMA).

Porous nanocomposites with a very low dielectric constant value of 2.73, were described by Jiao et al. [7].

The main objective of this work was the analysis of the microstructure and composition of glass-ceramic composites with porosity introduced into the internal part of multilayer structures fabricated by LTCC technology in order to decrease dielectric permittivity.

\section{Stages of LTCC substrate preparation}

Glass-ceramic composites based on ceramics mixed with large amounts of glass phase (40-60\%) are used for multilayer substrates and packages obtained by LTCC technology. Relatively low sintering temperature, inexpensive and nontoxic starting materials, dielectric constant and thermal expansion coefficient lower than those of $\mathrm{Al}_{2} \mathrm{O}_{3}$ are advantageous features of these materials.

The properties of a LTCC material can be modified at two levels of its preparation. The first level - preparation of a batch and milling of nonorganic compounds 
allows to choose the final chemical composition of a material with desired properties. The appropriate selection of the kind and ratio of ceramic and glass components in a green ceramic tape strongly determines mechanical and electrical properties of the final substrate and also allows to modify its sintering temperature. The second level of adjustment of LTCC material properties is slurry preparation. Slurry for tape casting is typically a liquid mixture of selected glass and ceramic powders with organic components playing a role of plasticizers, dispersants, solvents, and binders. There is also possibility to enrich slurry with so called pore formers (materials causing porosity in the sintered substrate).

In this work, LTCC porous composites based on $\mathrm{Al}_{2} \mathrm{O}_{3}$ or cordierite $\left(\mathrm{Mg}_{2} \mathrm{Al}_{4} \mathrm{Si}_{5} \mathrm{O}_{18}\right)$ ceramics and $\mathrm{SiO}_{2}-\mathrm{Al}_{2} \mathrm{O}_{3}-$ $\mathrm{B}_{2} \mathrm{O}_{3}-\mathrm{CaO}-\mathrm{MgO}$ glass (1:1 ceramic:glass weight ratio) were obtained as a result of graphite powder addition at the level of slurry preparation. The fired substrates are characterized by a significant porosity and a lowered value of dielectric permittivity $[8,9]$. In our study, to attain low dielectric constant, $25-50 \mathrm{wt} \%$ of fine graphite powder with about $1 \mu \mathrm{m}$ grain size was added as a pore former.

Green tapes $80-150 \mu \mathrm{m}$ thick were fabricated by tape casting of the slurry and drying for $24 \mathrm{~h}$ at temperature of $40^{\circ} \mathrm{C}$. In the next step of the LTCC process, green tapes were laminated into multilayer structures which after firing at $900^{\circ} \mathrm{C}$ turned into glass-ceramic composites with internal porous and external nonporous layers.

In previous work, dielectric parameters of the substrates were determined using LCR meter at frequency of $2 \mathrm{MHz}$ and at temperatures ranging from -55 to $150^{\circ} \mathrm{C}[8,9]$. The results of dielectric studies showed that in the case of $50 \%$ graphite addition, dielectric constant decreased from 8 for dense glass $-\mathrm{Al}_{2} \mathrm{O}_{3}$ substrates and 5.6 for dense glass-cordierite substrates to 3.0 and 2.94, respectively, for porous composites. Addition of $25 \%$ of graphite resulted in dielectric permittivity of 5.6 and 3.5 for glass $-\mathrm{Al}_{2} \mathrm{O}_{3}$ and glass-cordierite substrates [8, 9].

In this work, the effects of porosity introduction were investigated by a Hirox digital optical microscope, a scanning electron microscope (SEM) and energy dispersive spectroscopy (EDS). Besides the characterization of pore size, shape, and distribution, the impact of porosity on detrimental microstructure modification which could cause risk of mechanical weakness of the sintered structure was also analyzed.

\section{Microscopic and EDS analysis of glass-cordierite composites}

For the analysis of microstructure of green and fired composite structures, optical and scanning electron microscopy studies were carried out. Observations with the use of optical microscope of fractured cross-sections of green laminates allowed us to evaluate the quality of the tape and the correctness of the lamination process. Figure 1a,b shows images from the Hirox KH7700 microscope illustrating differences in the appearance of the fired glass-ceramic laminates with and without graphite powder added at the stage of slurry preparation. Analysis of the images of the sintered substrates consisting of non-porous external and porous inner layers showed that the surface of such substrates was smooth and suitable for screen printing. In contrast, when porous tape was used for external layers, porosity caused high roughness and absorptivity of the surface. Holes in the material, visible from the optical microscope images (Fig. 1a), could lead to penetration of the conductive paste during printing and to decrease of the pattern resolution. It was found that the applied lamination conditions ensured good connection of individual layers in the green multilayer laminates, both with and without graphite addition, as well as appropriate mechanical properties after firing.

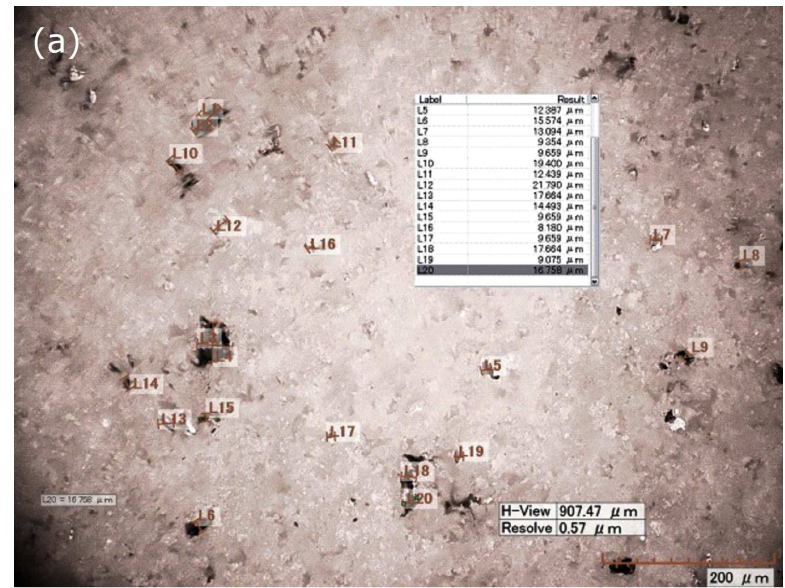

(b)

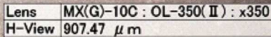

Fig. 1. Images from a Hirox optical microscope of the surface of fired glass-ceramic composites: (a) with graphite addition, (b) without graphite addition.

It was found that $28 \%$ of pores have a diameter below $10 \mu \mathrm{m}, 48 \%$ in the range $10-20 \mu \mathrm{m}$ and $24 \%$ above $20 \mu \mathrm{m}$. As illustrated by a SEM image in Fig. 2, there is a significant difference in porosity between the compact outer layers and the inner layers containing a porosity at a level of $30-50 \%$, resulting from the combustion of the graphite additive. 


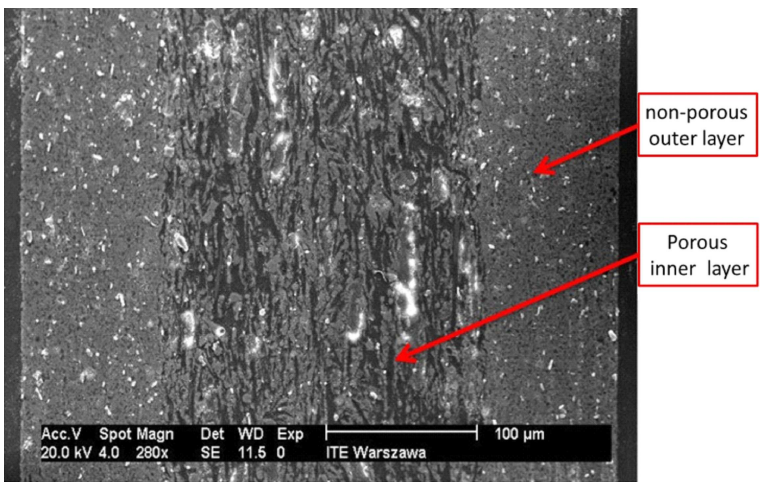

Fig. 2. SEM image of a glass-ceramic cross-section after firing - porous and nonporous layers.

As can be seen from Fig. 3a,b, the increase in graphite addition significantly increases porosity, but also influences its shape and arrangement. In the case of smaller amount of pores (25\% graphite additive) (Fig. 3a), pores are more circular and there is a lot of closed porosity, in contrast to the material with $50 \%$ of graphite additive (here porosity turned into irregular channels) (Fig. 3b).

Figure $4 \mathrm{a}-\mathrm{c}$ shows the microstructure and the EDS analysis in the regions of glass-ceramic samples where microcracks appeared. Such effect may originate from mismatch of thermal expansion coefficient of particular components of the composite, as well as may be due to phase transitions of $\mathrm{SiO}_{2}$ (being the main component of the applied glass) which occur during cooling and are accompanied with a significant volume change.
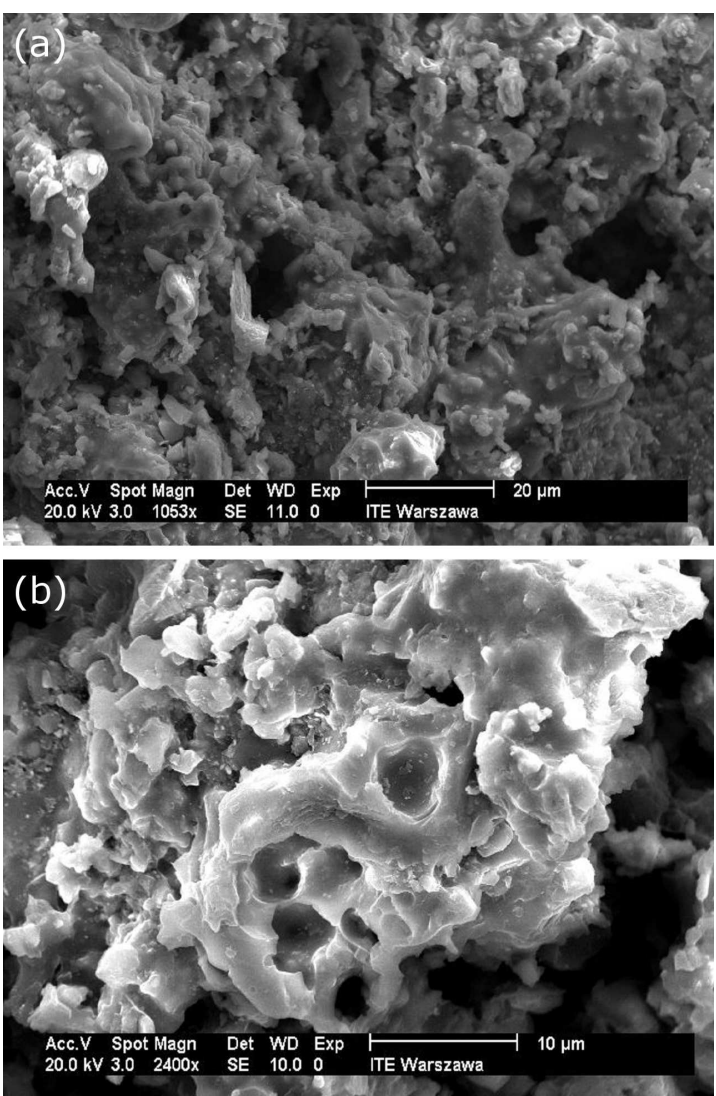

Fig. 3. SEM images of a composite cross-section after firing - porous layers. Graphite content in a slurry: (a) $25 \mathrm{wt} \%$, (b) $50 \mathrm{wt} \%$.
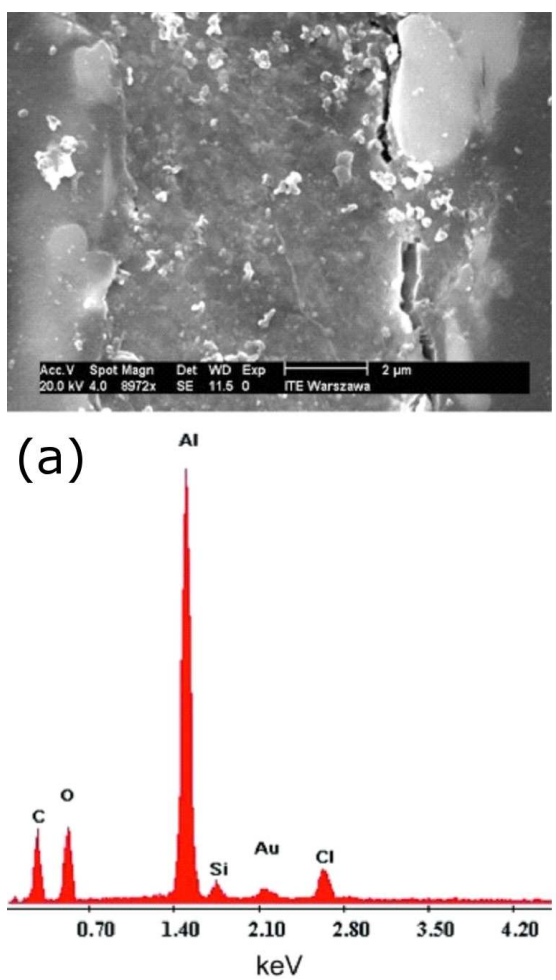
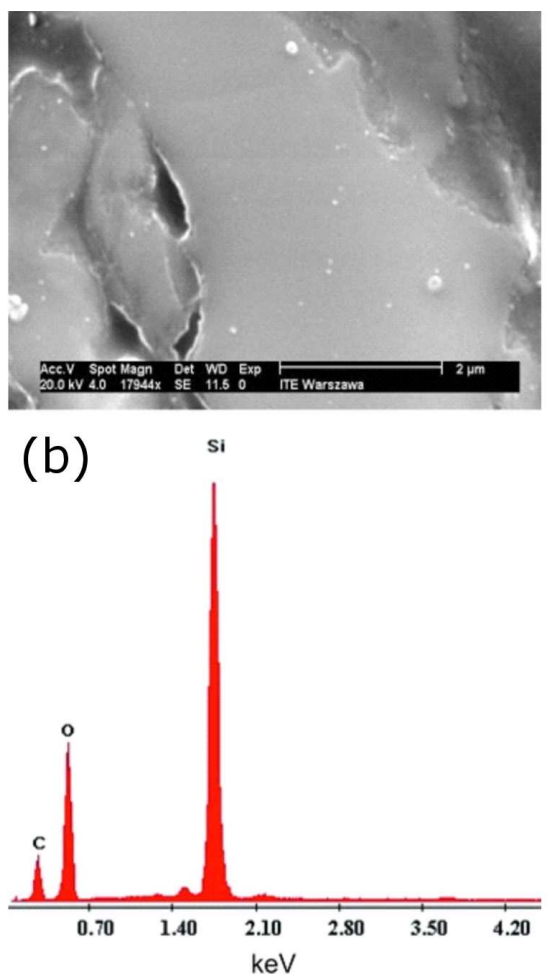

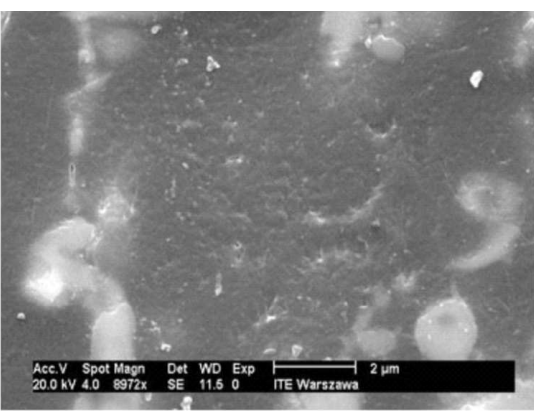

(c)

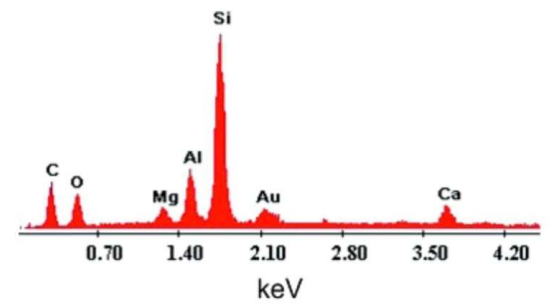

Fig. 4. SEM images of cross-sections of the fired glass-ceramic composite with corresponding EDS analysis. 


\section{Conclusions}

LTCC technology was successfully used for preparation of multilayer glass-ceramic substrates with non-porous outer layers and controlled porosity in their internal part. The analysis using SEM and EDS method of the developed porous composites based on glass- $\mathrm{Al}_{2} \mathrm{O}_{3}$ (or alternatively glass-cordierite) revealed their irregular microstructure and the presence of channel-shaped porosity. Porous substrates without dense external layers had rough surface and showed too high humidity absorption which was detrimental for high resolution printing. Too high content of graphite powder in the slurry led to decrease in quality and mechanical strength of the fired substrate. Irregular channels formed in the microstructure of a multilayer LTCC substrate can lead to its deformation and deterioration of dielectric parameters (high dielectric loss). There is a border contribution of graphite as a pore former that still allows obtainment of mechanically strong structure and leads to formation of closed pores instead of undesired irregular channels. This maximum level not causing potential risk of mechanical destruction of the substrates was found to be $25 \%$ of graphite in the inner layers of the developed LTCC composites.

\section{Acknowledgments}

This work has been partly financed by ITE Ph.D. project No. 53.06.008 and by the National Center for Research and Development (NCBiR) in Poland, contract No. PBS3/A3/18/2015.

\section{References}

[1] L. Li, C.H. Liu, J.Y. Zhu, X.M. Chen, J. Eur. Ceram. Soc. 35, 1799 (2015).

[2] C. Hu, P. Liu, Mater. Res. Bull. 65, 132 (2015).

[3] K. Ju, H. Yu, L. Ye, G. Xu, J. Am. Ceram. Soc. 96, 3563 (2013).

[4] M.M.S. Sanad, M.M. Rashad, E.A. Abdel-Aal, K. Powers, Mater. Chem. Phys. 162, 299 (2015).

[5] J. Zhou, J. Adv. Ceram. 1, 89 (2012).

[6] K. Keiichiro, Y. Shimada, J. Ceram. Soc. Jap. 100, 570 (1992).

[7] J. Jiao, I. Wang, P. Lv, P. Liu, Y. Cai, Mater. Lett. 109, 158 (2013).

[8] B. Synkiewicz, Microelectron. Int. 33, 124 (2016).

[9] B. Synkiewicz, D. Szwagierczak, J. Kulawik, Microelectr. Int. 34, 110 (2017). 